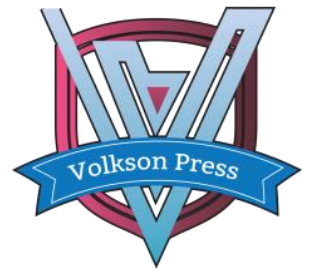

Contents List available at VOLKSON PRESS

Economics \& Management Innovations(EMI)

DOI : http://doi.org/10.26480/icemi.01.2017.313.315

\title{
Problem management in production processes with the use of A3 Report
}

\author{
Joanna Kotowska ${ }^{1,}{ }^{*}$, Anna Burduk ${ }^{1}$ and Mieczysław Jagodziński \\ ${ }^{1}$ Faculty of Mechanical Engineering, Wroclaw University of Science and Technology, Wroclaw, Lower Silesia Province, 50-370, Poland \\ ${ }^{2}$ Institute of Automatic Control, Silesian University of Technology, Gliwice, 44-100, Poland \\ “joanna.kotowska@pwr.edu.pl
}

This is an open access article distributed under the Creative Commons Attribution License, which permits unrestricted use, distribution, and reproduction in any medium, provided the original work is properly cited.

\section{ARTICLE DETAILS}

\section{Article History:}

Received 02 october 2017

Accepted 06 october 2017

Available online 11 october 2017

\section{Keywords:}

A3 Thinking Approach, A3

Problem Solving Report, Lean

Production.

\section{ABSTRACT}

This paper describes the possibility of application of a problem solving technique with the use of A3 Report for production problems (including technical problems with machines and equipment). The methodology of creating the document was described. There was also presented an example of the use of the A3 Report in one of Polish production companies.

\section{Introduction}

The production companies that try to operate in the spirit of kaizen use various Lean Management tools [1]. One of them is A3 Report which supports problem solving and introduction of new solutions. The aim of this study is to show a practical example of the use of A3 Report in the management of problems in production processes.

\section{A3 Thinking Approach}

\subsection{Idea of the approach}

A3 Report is not only a note on a sheet of paper with the format of $297 \mathrm{x}$ $420 \mathrm{~mm}$, although it has a lot in common also with it [2, 3]. It turns out that its roots reach many years ago when Toyota understood that each problem occurring in the company can and even should be described on a single sheet of paper so that any person dealing with a given problem has an opportunity to see it from the same perspective $[2,4,5,6]$. Although the main way of thinking used in A3 Reports is always based on the same logic, the format and vocabulary used are flexible and can be adjusted to specific needs. Speaking in the most general term, A3 Report is a powerful tool for problem solving, improvement and effective implementation of plans [4]. This is a way to illustrate the thinking process that occurs when solving the problems - a continuous dialogue between the problem owner and other people in a given organization. [7]

\subsection{The methodology used}

The basic method, on the basis of which a report is created, is the Deming cycle, i.e. "Plan, Do, Check, Act". When developing each subsequent item of the document, the 5 Whys technique is also widely used. The cause-andeffect analysis is most frequently supported by the Ishikawa Diagram. In turn, the collection of data requires Gemba walks (i.e. in the case of production processes - going to the production floor and directly examining the problem). $[2,4,5,6,7]$

\subsection{Manner of creating the document}

The document (Fig. 1), as its name indicates, should include 1 sheet of paper in A3 size, i.e. the largest sheet of paper that can go through a fax [2]. At the top, it should contain a title (clear, concise and specific naming of the problem is the key to success) and a signature (to unequivocally indicate the "owner" of the problem). It is also advisable to place the date in order to distinguish the current version from others. In the next step, the current conditions should be described. The description should be concise, transparent and supported by facts, which is mostly achieved by the use of graphs, diagrams, etc. [3] containing also numerical statistics. After examining the current situation, the goal should be defined, i.e. the desired future situation expressed in numbers. When the discrepancy between the current state and the desired state is known, the cause and effect relationships should be found in order to identify its cause. This step requires an in-depth analysis, so it is advisable to use the " 5 Why" technique and Ishikawa Diagram. The fifth field of the sheet is the definition of the remedial measures, i.e. a proposal of specific activities aimed at achieving the target situation. A dialogue with the persons involved in the problem constitutes a good preparation. It is worth presenting some ideas for a solution to all the persons concerned, asking about their opinions and then selecting the best possible solution. It should be examined which remedial measures are possible at all and then check which of them could really be used in practice. The area entitled "Plan" contains a precise description of the action plan, i.e. what actions are to be done, by whom and when in order to achieve the goal, and what mechanisms will be used to monitor its implementation. The Deming cycle is helpful in preparation of a precise plan that will enable the introduction of remedial measures. This cycle is also helpful in planning the actions when the course of events is not in line with the intentions. The last item of A3 Report includes further actions. It should be ensured that the welldeveloped process functions all the time in accordance with the assumptions. The whole team should be informed about the possible solutions to potential problems. $[5,7,8]$

\begin{tabular}{|l|l|}
\hline TITLE & \multicolumn{1}{|c|}{ OWNER/ DATE } \\
\hline $\begin{array}{l}\text { 1. DESCRIPTION OF THE SITUATION } \\
\text { Identification of problem or need }\end{array}$ \\
\begin{tabular}{|l|l|}
\hline $\begin{array}{l}\text { 2. CURRENT CONDITIONS } \\
\text { Understanding the current situation }\end{array}$ \\
\hline $\begin{array}{l}\text { 3. GOALS/ MEASURES } \\
\text { Determining the target state }\end{array}$
\end{tabular} \\
\hline $\begin{array}{l}\text { 4. ANALYSIS REMEDIAL MEASURES } \\
\text { Cause and effect analysis } \\
\text { to achieve the goal }\end{array}$ \\
\hline
\end{tabular}


Fig. 1: Structure of the A3 Report

\section{Practical application of A3 Report}

\subsection{Selected company}

A practical application of A3 Report for supporting the process of solving production problems is demonstrated on the example of a Polish factory producing aluminium alloys. The input material for the alloys is aluminium waste, e.g. chips. Still before loading to a furnace, they need to be dried and filtered in a machine. The most polluted scrap is subject to preliminary melting in a rotary kiln where the most valuable part of the waste is recovered. The main remelting takes place in four melting furnaces, from which aluminium is poured to ladles or moulds after an appropriate specification of the alloy has been obtained.

\subsection{Problem with drying of chips}

When analyzing the course of the production in the company, most observations concerned the chip drying operation, the poor efficiency of which caused a delay in the entire alloy production process. The records from the observations concerned:

1. Insufficient supervision of the control panel of the machine (a failure to keep appropriate time intervals by the operator);

2. Incorrectly completed control sheet (time intervals and speed of the apron feeder falsely stated by the operator) or a failure to complete it at all (when the operator is replaced by other workers);

3. Exceeding the permissible temperature in the rotary kiln;

4. Exceeding the permissible temperature of the secondary combustion in the absence of the operator;

5. Unreliable dryer system which should inform about irregularities;

6. Excessive smoke from the rotary kiln in connection with the new technology being tested (the operator was not notified about it and reduced the machine parameters in response to the hazardous situation);

7. Mixing chips from different producers in one box;

8. Downtimes in connection with failures of the dryer (errors of burners, burning chips, defective material);

9. Chips separator and apron feeder operating when the chips dispenser is empty.

\subsection{Problem management with the use of A3 Report}

Suspecting that the problems stem generally from a lack of an appropriate communication system, a decision was made to use A3 sheet (Fig. 2) for the problem being analyzed. The document was created on the basis of Gemba walks, continuous observations, an in-depth analysis of indicators, and regular talks with employees. To illustrate the problems, a graphical form of the collected numerical data was used. The target was to have $100 \%$ of information on all downtimes and irregularities in the operation of the machines as of the end of the current year. Ishikawa Diagram based on the $4 \mathrm{M}$ principle was used for the cause and effect analysis. The findings from the analysis suggested that there were three main root causes:

1. No automatic system to stop the operation of the machine when the permissible maximum temperature is exceeded;

2. No automatic registration of the operation and parameters of the dryer;

3. No ongoing control of the operation of the machines resulting from duties of operators in other departments.

On the basis of the data collected, an interdisciplinary team proposed the implementation of four basic remedial measures:

1. Installation of an automatic system at the dryer, which stops the operation, when the permissible maximum temperature is exceeded;

2. Installation of a program, which registers downtime of machines and cases of exceeding the permissible maximum temperature in furnaces;

3. Systematizing the boxes - allocation of one of them only for the feedstock that has been checked (tests of the dryer would be more reliable, if one type of chips was used in them);

4. Informing the workers of the receiving warehouse about undesirable objects in chips (including plugs which cause frequent downtimes of the dryer). were assigned to each task. As a part of the implementation of the first two items, GOLEM SuperVisor OEE Next software was proposed.

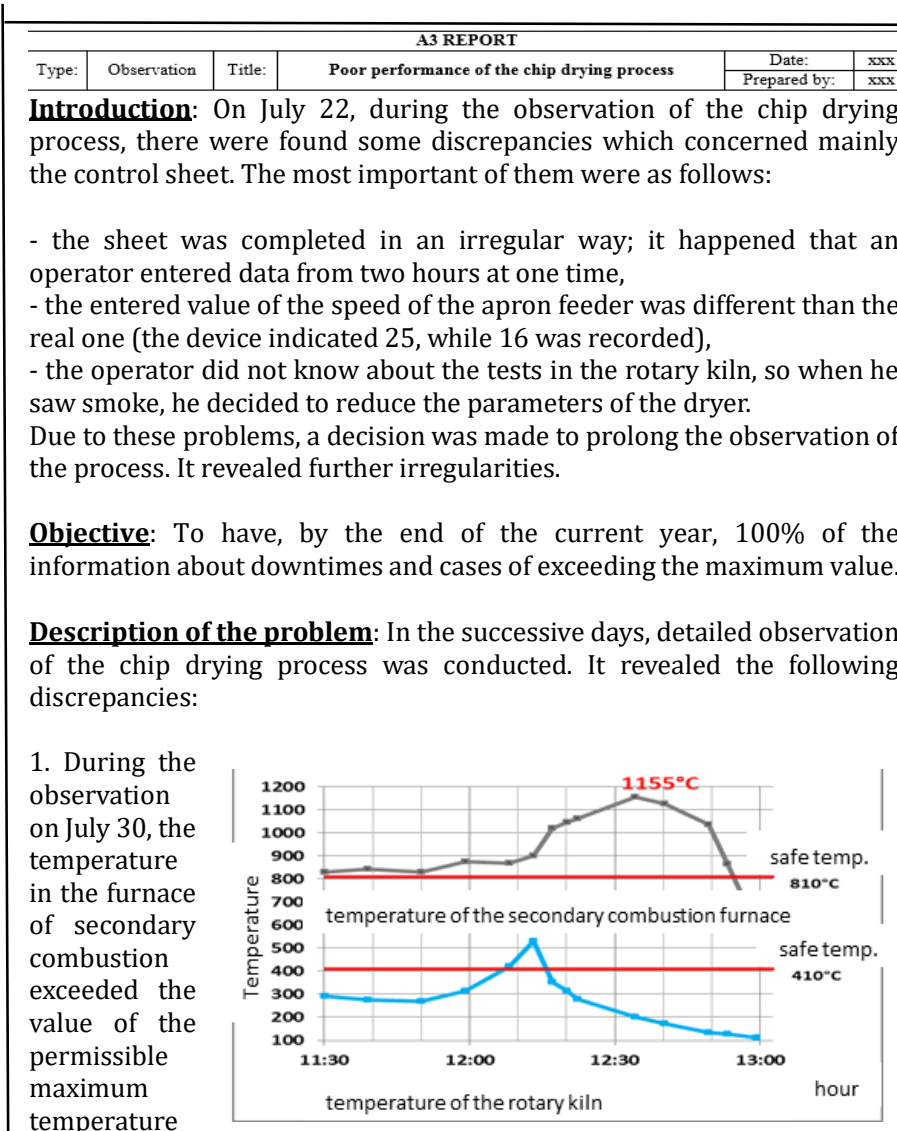
temperature

by more than $300^{\circ} \mathrm{C}$. While this temperature was growing rapidly, a completely opposite situation took place in the rotary kiln, where the temperature dropped below the acceptable level. Probably it was a failure of a dryer system that informs about malfunctions of the burner. The device continued to operate and gas penetrated to the secondary combustion furnace, which caused a dramatic increase in the temperature. The operator, when checking the condition of the dryer, did not see the flame and turned off the machine at 12:54.

2. The sheet was not completed correctly:
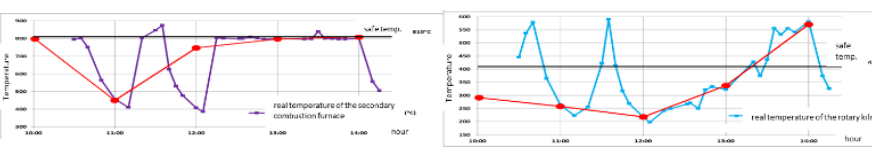

3. On July 26, a test on AMS chips was carried out; it revealed their tendency to burning in the rotary kiln. Half an hour after the loading, the temperature in the rotary kiln was rapidly growing; this was still happening for several minutes after the restart of the dryer. At the culminating moment, the temperature reached $606^{\circ} \mathrm{C}$.

4. The dryer shutdown report indicates that the downtime on 29/07 took place between 7:50 am and 9:15 am. In fact, the machine was started up again only at 11:18 am. The control sheet has not been completed since 8:00, so information about the time when the operation of the dryer was started is not included in it. Furthermore, the dryer shutdown report has been completed by only one operator since the time of the shutdown.

5. The plugs brought together with chips repeatedly caused failures of the dryer. Apart from the defects that had been occurring earlier, such as jamming of the bucket conveyor, the plugs also damaged other components, e.g. the mechanism of the apron feeder.

6. It happened several times that the chips dispenser was empty and thus the operation of the chip separator and the apron feeder was redundant.

\section{Analysis:}




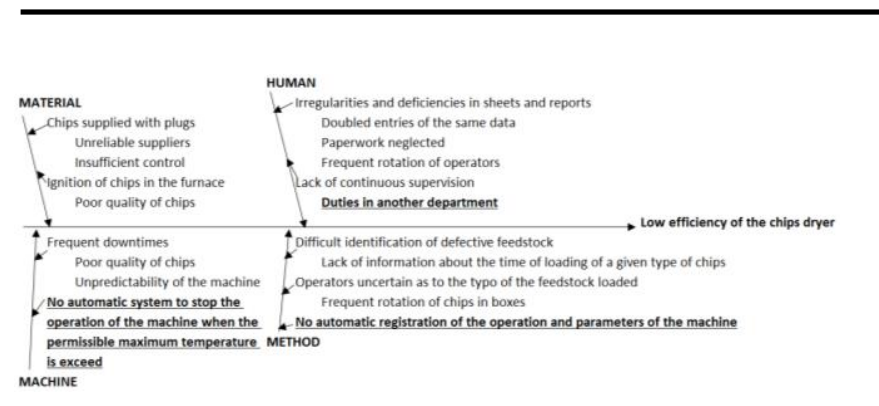

\section{Root causes:}

1. No automatic system to stop the machine when the permissible maximum temperature is exceeded.

2. A lack of an automatic registration of the operation and parameters of the machine.

3. Operators do not always control the operation of the machine, because they have duties also in another department.

\section{Recommended remedial measures:}

\begin{tabular}{|l|c|c|}
\hline \multicolumn{1}{|c|}{ WHAT } & WHO & WHEN \\
\hline $\begin{array}{l}\text { 1. Installation of an automatic system at the dryer, } \\
\text { which would stop the operation of the dryer, when } \\
\text { the permissible maximum temperature is } \\
\text { exceeded. }\end{array}$ & $\mathrm{xxx}$ & $\mathrm{xxx}$ \\
\hline $\begin{array}{l}\text { 2. Installation of a program at the dryer, which } \\
\text { would allow registering all the downtimes of the } \\
\text { machine and inform about each case of exceeding } \\
\text { the permissible temperature in the furnace. }\end{array}$ & $\mathrm{xxx}$ & $\mathrm{xxx}$ \\
\hline $\begin{array}{l}\text { 3. Systematizing the boxes - allocation of one of } \\
\text { them only for the feedstock that has been checked. }\end{array}$ & $\mathrm{xxx}$ & $\mathrm{xxx}$ \\
$\begin{array}{l}\text { The tests of the dryer would be more reliable, if one } \\
\text { type of chips was used in them. }\end{array}$ & \\
\hline $\begin{array}{l}\text { 4. Informing the workers of the receiving } \\
\text { warehouse about undesirable objects in chips, } \\
\text { including plugs which cause frequent downtimes } \\
\text { of the dryer. }\end{array}$ & $\mathrm{xxx}$ & $\mathrm{xxx}$ \\
\hline
\end{tabular}

Assessment of the effectiveness: Checking the level of information about downtimes at the end of the current year.

\section{Fig. 2: A3 Report for the process of drying of chips}

\section{Conclusions}

A3 Report is a relatively simple but very effective method of communication in a company. When properly used, it can become a management tool in a company - it helps make decisions based on proven facts, implement effective remedial measures and thereby maintain continuous improvement. A3 Report is used in Polish production companies too (also for the management of technical problems). This paper presents an example of the practical use of this document which became the main carrier of information about problems arising in the chip drying process. The remedial measures are still at the stage of the implementation, but an improvement in functioning of the analysed process was noticed already after the first actions.

\section{References}

[1] Jasiulewicz-Kaczmarek M., Saniuk A., How to make maintenance processes more efficient using lean tools? in: R. H.M. Goossens (eds.) Advances in Social and Occupational Ergonomics: Proceedings of the AHFE 2017 Conference on Social and Occupational Ergonomics, July 17-21, 2017, Los Angeles, California, USA Series: Advances in Intelligent Systems and Computing, Vol. 605, pp. 9 - 20, 2018

[2] J.A. Bassuk, I.M. Washington: The A3 Problem Solving Report: A 10-Step Scientific Method to Execute Performance Improvements in an Academic Research Vivarium, in: PLoS ONE 8(10) (2013)

[3] S.S. Chakravorty: Process Improvement: Using Toyota A3 reports, in: Quality Management Journal Vol. 16 Issue 4 (2009).

[4] D.K. Sobek, A. Smalley: Understanding A3 thinking: a critical component of Toyota's PDCA management system, CRC Press, New York (2008).

[5] N.M. Saad, A. Al-Ashaab, M. Maksimovic: A3 thinking approach to support knowledge-driven design, in: The International Journal of Advanced Manufacturing Technology Vol. 68 Issue 5 (2013).

[6] J.S. Anderson, J.N. Morgan, S.K. Williams: Using Toyota`s A3 Thinking for Analysing MBA Business Cases, in: Decision Sciences Journal of Innovative Education (2011).

[7] J. Shook: Managing to Learn: using the A3 management process to solve problems, gain agreement, mentor and lead, Lean Enterprise Institute, Cambridge (2008).

[8] N.M. Saad, A. Al-Ashaab, M. Maksimovic: A3 Thinking Approach to Support Problem Solving in Lean Product and Process Development, in: J. Stjepandić, G. Rock, C. Bil (eds) Concurrent Engineering Approaches for Sustainable Product Development in a Multi-Disciplinary Environment, Springer, London (2013).

[9] K. Skrzypek, K. Dąbrowski, M. Wojciech, S. Kłos: Analysis of innovation levels exhibited by Polish manufacturing companies in the metal and automotive industries, In: Innovation Management, Development Sustainability, and Competitive Economic Growth - Vision 2020. International Business Information Management Association (IBIMA), pp. 3017-3033, (2016).

[10] Rudawska A., Čuboňova N., Pomarańska K., Stanečková D, Gola A.: Technical and Organizational Improvements of Packaging Production Processes, Advances in Science and Technology. Research Journal, Vol. 10, No. 30, pp. 182-192, (2016).

[11] Grzybowska K., Hoffa P.: Approving with application of an electronic bulletin board, as a mechanism of coordination of actions in complex systems, Distributed Computing and Artificial Intelligence, 12th International Conference Advances in Intelligent Systems and Computing, Vol. 373, S. Omatu, et al. (Eds.), pp. 357-365, (2015) 